HID 42 (2015)

\title{
EL ARZOBISPO DON PEDRO DE CASTRO CABEZA DE VACA Y QUIÑONES Y LA INFLUENCIA DEL SACRO MONTE EN EL DESARROLLO INMACULISTA EN GRANADA ${ }^{1}$.
}

\author{
THE ARCHBISHOP DON PEDRO DE CASTRO CABEZA DE VACA Y \\ QUIÑONES AND THE INFLUENCE OF THE SACRO MONTE IN THE \\ IMMACULIST DEVELOPMENT IN GRANADA.
}

\author{
José Antonio Peinado Guzmán \\ Universidad de Granada \\ pepeinado@hotmail.com
}

Resumen: La figura del arzobispo don Pedro de Castro fue enormemente importante para el desarrollo de la devoción inmaculista en la Granada de finales del siglo XVI y comienzos del siglo XVII. A raíz de los famosos descubrimientos del Sacro Monte, se va a producir una evolución de esta creencia en tierras granadinas a instancias de este prelado, quien tomó el asunto como una de sus prioridades personales en su episcopado. El inteligente manejo del tema por parte del arzobispo, a pesar de que los hallazgos del Sacro Monte fueran condenados posteriormente por Roma, terminaría concretándose en la erección de la Abadía, en el uso ideológico de todo ello, así como en la extensión del concepcionismo en Granada.

Palabras ClaVe: Granada, Sacro Monte, inmaculismo, Pedro de Castro, siglo XVII, teología.

ABSTRACT: The figure of archbishop don Pedro de Castro was extremely important for the development of immaculist devotion in Granada in the $16^{\text {th }}$ century and beginning of the $17^{\text {th }}$ century. In the wake of the famous discoveries of the Sacro Monte, it will produce an evolution of this belief in land Granada at the request of this prelate, who took the issue as one of his personal priorities in his episcopate. Intelligent handling of the issue by the Archbishop, while the findings of the Sacro Monte were subsequently convicted of Rome, eventually landing in the erection of the Abbey, in the ideological use of all of this, as well as the extension of the conceptionism in Granada.

Keywords: Granada, Sacro Monte, immaculism, Pedro de Castro, $17^{\text {th }}$ century, theology.

1. Abreviaturas utilizadas. ASM = Archivo del Sacro Monte; ACGr = Archivo de la Catedral de Granada; AHDGr = Archivo Histórico Diocesano de Granada. 


\section{RESEÑA BIOGRÁFICA}

Don Pedro de Castro Vaca (o Cabeza de Vaca) y Quiñones había nacido en 1534 en Roa (Burgos) ${ }^{2}$. Hijo de don Cristóbal Vaca de Castro, hombre de alto rango, puesto que llegó a ser capitán general y gobernador del Perú. El que fuera prelado granadino, se caracterizó por ser una persona de gran capacidad intelectual y de vasta formación, especialmente en cuestiones jurídicas. Muestra de esto es que hubo de defender a su padre ante los Consejos de Indias y de Castilla por diversos cargos, entre los que destacaba el de fraude fiscal.

Ordenado sacerdote en 1561, entre 1562-1564 toma un primer contacto con Granada, al ser nombrado visitador de la Capilla Real, Hospital Real, Colegio Real y de la Universidad. Designado primero como oidor de la Chancillería de Granada, accedería posteriormente a su presidencia en 1578. En 1583 obtendría similar cargo en Valladolid. Poco antes de ser elegido para la sede granadina, en 1588, se graduará como Doctor en Sagrados Cánones por la Universidad de Valladolid.

Electo como prelado de dicho arzobispado en diciembre de 1589, tomará posesión del mismo el 15 de abril del siguiente año. En 1610 sería nombrado como arzobispo de Sevilla, donde permanecería hasta su muerte, acaecida a los 89 años, en 1623.

Uno de los pilares que centraron su labor pastoral fue su inflexible sentido de la moralidad. Su concepto social se resumía en el catolicismo de Estado, en connivencia con la monarquía. Para ello, luchó contra todos los vicios y relajación de buenas costumbres que alejaban de este propósito. Particularmente, una de sus obsesiones fue la prostitución ${ }^{3}$, persiguiéndola denodadamente y creando para ello en la capital granadina el Beaterio de las Recogidas de Santa María Egipciaca. En favor de la educación femenina, fundó el Colegio de Niñas en dicha ciudad, para que doncellas pobres y nobles fuesen formadas hasta su casamiento. Asimismo, se mostraba contrario a que las mujeres vistiesen indecorosamente, de igual modo que luchó contra las comedias, tanto que participasen en ellas mujeres solteras, como que eclesiásticos asistiesen a las citadas funciones.

A la par que el arzobispo mostraba un talante estricto y exigente en materia moral, mantenía, asimismo, una actitud caritativa y desprendida. Su enorme fortuna, tal y como nos relatan Bermúdez de Pedraza y Henríquez de Jorquera, fue

2. Las notas bibliográficas que recojo están extraídas de: D.N. Heredia y Barnuevo. Místico ramillete. Vida de D. Pedro de Castro, fundador del Sacromonte. (Edit.) M. Barrios Aguilera. Granada, 1998, pp. IX-XXVI. Asimismo, hemos de destacar otras publicaciones sobre este personaje: J.A. Ollero Pina. "La carrera, los libros y la obsesión del Arzobispo D. Pedro de Castro y Quiñores (1534-1623), en De libros y bibliotecas: homenaje a Rocio Caracuel. (Coord.) S. Celestino Angulo, Sevilla, 1994, pp. 265-276; Mª. García Valverde. "La donación del arzobispo Don Pedro de Castro al Sacromonte: el inventario de sus bienes", Cuadernos de arte de la Universidad de Granada 27 (1996), pp. 283-295; M.A. Díaz Gito. “Calvete de Estrella y Pedro de Castro y Quiñones, arzobispo de Granada", en Benito Arias Montano y lo humanistas de su tiempo. (Coord.) J.Ma Maestre Maestre et alii, 2006, pp. 789-804.

3. Un detalle de esta rigidez lo encontramos en J. Antolínez de Burgos. Historia eclesiástica de Granada. (Edit.) M. Sotomayor. Granada, 1996, p. 386. 
destinada a sustanciosas limosnas y obras pías. Todo esto era combinado con un talante absolutamente austero, pobre y humilde, convirtiéndole, en este sentido, en un modelo de vida cristiana, según cuentan estos historiadores ${ }^{4}$. No en vano, en más de una ocasión, sopesó la idea de retirarse a la ascética vida cartujana. A todo esto habría que unirle su carácter enormemente áspero, que le granjeó no pocos enfrentamientos.

Desde el punto de vista de su actividad como prelado, se caracterizó por la aplicación de su rigidez moral en las costumbres de su clero. Intentó su reforma exigiendo una fuerte disciplina, con el fin de erradicar vicios adquiridos. Asimismo, se opuso a la fundación de nuevos conventos en Granada, realizó varias visitas pastorales por toda la diócesis y, dependiendo de su fundación sacromontana, ideó las denominadas misiones en favor de la evangelización de los territorios más deprimidos de la diócesis.

Otro de los frentes que tuvo que abordar fue el de la reconstrucción de numerosos templos tras la reciente Guerra de las Alpujarras. Hubo de restaurar numerosas iglesias arrasadas y construir otras de nueva edificación. Además de esto, continuó con las obras de la catedral. En este aspecto, su aportación fue meramente funcional, dotando los espacios básicamente de lo necesario, evitando lujos superfluos. En cambio, donde sí puso todo su empeño y procuró ejecutar su gran obra, fue sin duda la abadía del Sacro Monte. Encargada en un principio a Ambrosio de Vico, fue realizado un nuevo proyecto por el jesuita Pedro Sánchez en 1614, ya que el primero no satisfizo las aspiraciones que el arzobispo tenía para dicho edificio. La muerte del prelado cercenó tan grandiosa empresa, no llegándose nunca a finalizar dicho deseo en su totalidad. Aun así, el hecho de aceptar la sede de Sevilla en 1610, fue en parte debido a su compromiso con el Sacro Monte, ya que suponía una fuente de ingresos considerable para finalizar tan magna obra ${ }^{5}$. En este sentido, cabe reseñarse la importante crítica que en la diócesis sevillana recibió, debido a las ingentes cantidades de dinero que de allí mandaba para la construcción abacial.

Finalmente, cabe hacer una pequeña mención a su faceta de experto jurista. Defendió con enorme celo los derechos eclesiásticos frente a lo que él consideraba injerencias de la Corona. Varios son los conflictos que mantuvo tanto con los reyes como con la Real Chancillería ${ }^{6}$. De igual modo, fueron constantes sus litigios con la Universidad, debido a su afán de controlarlo todo. Frente a los deseos de la institución académica de emanciparse de sus orígenes eclesiásticos, el prelado insistía en la sujeción y mantenimiento de dicho status fundacional.

\footnotetext{
4. F. Bermúdez de Pedraza. Historia eclesiástica de Granada. Granada, 1989, f. 266 r.

5. Ibidem, f. 279 r. Igual referencia en F. Henríquez de Jorquera. Anales de Granada. (Edit.) A. Marín Ocete. Granada, 1987, p. 563.

6. Véase F. Bermúdez de Pedraza. Historia eclesiástica de Granada..., ff. 265 v-266r; 274 v-277 v, y sobre todo en: J. Antolínez de Burgos. Historia eclesiástica de Granada..., pp. 397-410.
} 


\section{Los Descubrimientos del Sacro Monte}

En lo que propiamente alude a la temática inmaculista ${ }^{7}$, la llegada al episcopado granadino de don Pedro de Castro y Quiñones, supuso un antes y un después en cuanto a su desarrollo se refiere. Ferviente defensor de dicho misterio, los acontecimientos que se sucederían a lo largo de su mandato, irían reafirmando sus convicciones con fe ciega. Tal es así, que el hecho de haber creído encontrar en los hallazgos sacromontanos una prueba evidente de la concepción inmaculada de la Virgen, hizo que, por esta convicción firme en tal privilegio mariano, admitiese como veraces e indiscutibles verdades todo lo encontrado en dicho entorno. Su devoción por la Inmaculada, en cierto modo, le hizo sostener con solidez la autenticidad de lo que, ya en aquella época, generaba no pocas dudas. Todo aquel conjunto de fabulaciones que, objetivamente, no tenían argumentación fuerte, fueron ardientemente defendidas por este obispo. Su celo pasional en dicha cuestión arrastró, asimismo, a una sociedad granadina que, a finales del Quinientos, buscaba una identidad propia. De alguna manera, con su credulidad, él mismo se convertía en uno de los falsarios ${ }^{8}$. En aquel contexto histórico, donde el conflicto entre moriscos y cristianos viejos seguía aún candente, estos sucesos supusieron, de manera indirecta, un nexo de unión entre ambas posturas y un porqué colectivo. No olvidemos que en juego estaban las raíces cristianas de Granada y su origen, nada menos que apostólico.

Es difícil explicar lo que para aquellas gentes significaron todos estos acontecimientos. La rapidez de los mismos fue complicada de digerir y la importancia de lo que se creía haber encontrado, favoreció aún más la credulidad. Por esta razón, el tema del Sacro Monte resulta embarazoso a la hora de abordarlo. Numerosas publicaciones se han encargado de reflexionar sobre el mismo. Aun así, a ellas nos remitimos para no caer en una reiteración manida ${ }^{9}$. Nos centraremos, pues, en

7. A modo de breve introducción acerca del inmaculismo, véase J.A. Peinado Guzmán. Controversia teológica. Devoción popular. Expresión plástica. La Inmaculada Concepción en Granada. Granada, 2012, pp. 88-234.

8. Esta idea la plantea Barrios Aguilera del siguiente modo: ¿Acaso el crecimiento doctrinal que se observa en los contenidos de los libros desde su inicio hasta el final (en esos cinco años de los hallazgos), y la creación sobre la marcha de los sucesivos una vez comprobado el éxito de los primeros no pudo deberse, con toda probabilidad al aliento que insuflaba en los falsificadores el apoyo entusiasta del prelado? Indirectamente, pues no hay evidencias documentales de otra cosa, Castro se convertia en falsario; los que materializaban el fraude eran a su manera intérpretes de los anhelos del prelado. Sabido es el riguroso control de los traductores e intérpretes, a los que presionaba sin recato en el matiz de sus versiones, la actividad descarada de sus agentes en la compra de voluntades, el rechazo airado, cuando no la persecución, de los renuentes, etcétera. M. Barrios Aguilera. "Pedro de Castro y los Plomos del Sacromonte: invención y paradoja. Una aproximación crítica", en Los plomos del Sacromonte. Invención y tesoro. Valencia, 2006, p. 42.

9. Aparte de la bibliografía que citamos, otros textos reseñables relacionados con el Sacro Monte serían: J. Ramos. El Sacro Monte de Granada. Madrid, 1883; Z. Royo Campos. El insigne Colegio del Sacromonte y la Universidad de Granada. Granada, 1954; Z. Royo Campos, Don Pedro de Castro, caudillo insigne del concepcionismo en España. Granada, 1954; Z. Royo Campos. Albores del Sacromonte. Granada, 1958; Z. Royo Campos. Reliquias martiriales del Sacromonte. Granada, 1960; J.M. Pita Andrade. Museo del Sacromonte. Granada, 1964; D. Cabanelas. El morisco granadino Alonso del 
la cuestión que nos concierne, la relación de los hallazgos sacromontanos con el asunto inmaculista. Su nexo de unión, evidentemente, será el arzobispo don Pedro de Castro.

A modo de breve resumen, recordaremos someramente la sucesión de hechos ${ }^{10}$. A finales del episcopado de don Juan Méndez de Salvatierra, concretamente el 18 de marzo de 1588, al derribar el alminar de la antigua Mezquita Mayor para la construcción de la nueva catedral, se encontró una caja de plomo que contenía una serie de objetos. En el interior de la misma se guardaba un lienzo triangular, un hueso y un pergamino escrito en árabe, castellano y latín. Según la narración del Marqués de Estepa, parece ser que también se halló un cuadro pequeño con una imagen de la Virgen pintada muy a lo antiguo en trage Egipciano con el niño en braços; que tenia una mançanita dorada en la mano, y encima della una cruz ${ }^{11}$.

Traducido el texto encontrado, se supo lo que supuestamente eran aquellos descubrimientos. Según se narraba, el presbítero Patricio, discípulo del primer obispo de Granada, había recibido el encargo de éste de esconder dicha caja para que no cayese en manos de los moros. Asimismo, se explicaba lo que contenía el cofre: una profecía del evangelista Juan sobre el fin del mundo, un trozo del paño con el que la Virgen secó sus lágrimas en la pasión de Cristo y un hueso de San Esteban protomártir. La profecía joánica había sido entregada a Cecilio por San Dionisio Areopagita en Atenas, cuando el prelado regresaba de Tierra Santa.

Pocos días tardó en certificarse la veracidad de aquellos objetos. Informadas la nunciatura y la secretaría del rey, a fecha de 5 de abril, se refrendó la autenticidad de lo hallado. La muerte del obispo Méndez de Salvatierra paralizó todo el proce-

Castillo. Granada, 1965; D. Sánchez-Mesa Martín. "Aportaciones al estudio de la escultura religiosa en el Sacromonte", en La Abadía del Sacromonte. Exposición artístico-documental. Estudios sobre su significación y orígenes. Granada, 1974; C. Alonso. Los apócrifos del Sacromonte (Granada). Estudio histórico. Valladolid, 1979; A. Bonet Correa. "Entre la superchería y la fe: el Sacromonte de Granada", Historia 16, 61 (1981); J. Caro Baroja. Las falsificaciones de la Historia en relación con la de España. Barcelona, 1992; M. Barrios Aguilera. "Moriscos y cristianos en el orto de la Granada Moderna", en Jesucristo y el Emperador cristiano, Córdoba, 2000.

10. Para toda esta cuestión, aparte de la bibliografía ya citada, ha sido indispensable la consulta de los siguientes documentos: F.J. Martínez Medina. "El Sacromonte de Granada y los discursos inmaculistas postridentinos", Archivo Teológico Granadino 59 (1996), pp. 5-57. De este artículo, encontramos una versión más reciente e insertada en la temática del aniversario de la proclamación del dogma inmaculista en: F.J. Martínez Medina. "El Sacromonte de Granada: impulsor de la Inmaculada Concepción en la Contrarreforma", en A María no tocó el pecado primero. "La Inmaculada en Granada”. Córdoba, 2005, pp. 119-155. Acerca de esta cuestión, ha sido indispensable la consulta de los siguientes artículos: F.J. Martínez Medina. "El Sacromonte de Granada y los sacromontes: mito y realidad", Proyección 44 (1997), pp. 3-22, F.J. Martínez Medina. "El Sacromonte de Granada, un intento de reinculturación entre la guerra de los moriscos y su definitiva expulsión", Chronica Nova 25 (1998), pp. 349-379, F.J. Martínez Medina. "Los Libros Plúmbeos del Sacromonte de Granada", en: Jesucristo y el Emperador cristiano. Córdoba, 2000, pp. 619-643, F.J. Martínez Medina. "Los hallazgos del Sacromonte a la luz de la Historia de la Iglesia y de la teología católica”, Al-Qantara 23 (2002), pp. 437-475.

11. A. Centurión. Información para la historia del Sacro monte, llamado de Valparaiso y antiguamente Illipulitano junto a Granada. S. 1., s. a. (Copia digitalizada de la Biblioteca Virtual de Andalucía), f. 9 v. Como anécdota, se comenta cómo el obrero que la encontró, Francisco Cano, la robó en un principio, entregándola a las autoridades días después por temor. 
so, aunque el Cabildo pidió la continuidad del mismo, en favor de la calificación de las reliquias y el pergamino.

La llegada de don Pedro de Castro a la sede granadina reabrió el tema, ya que él, personalmente, se interesó por el mismo. Aun así, la cuestión se mantuvo aparcada a la espera de nuevos acontecimientos.

A pesar de que desde el comienzo, el asunto generaba no pocas dudas en cuanto a su autenticidad, el interés que suscitaba era inusitado, constituyéndose en la antesala de lo que siete años después acaecería.

A partir de febrero de 1595 se sucederían una serie de nuevos hallazgos que durarían hasta 1599. Los primeros descubrimientos fueron unas láminas de plomo, con caracteres latinos que relataban la existencia en aquel paraje de los restos martirizados de diferentes santos, en concreto, de San Mesitón, San Hiscio y sus discípulos Turilo, Panucio, Maronio y Centulio. Días después, las de San Tesifón, Maximino y Lupario. Ahora bien, las últimas halladas fueron las más importantes. Entroncando con lo encontrado años atrás, se descubriría lo que, supuestamente, serían los restos martirizados de San Cecilio, primer obispo de Granada, y de sus seguidores San Setentrio y Patricio. En aquella Granada a caballo entre el XVI y el XVII, aquellos datos venían a confirmar las raíces apostólicas de la ciudad, ya que Cecilio era discípulo de Santiago. Después de largos siglos de dominio musulmán, estos hallazgos venían a significar un enlace entre aquellas comunidades cristianas primitivas y la reinstauración de la fe que se procuraba realizar ${ }^{12}$. Todo ello, en un contexto donde cualquier referencia que aludiese a la Antigüedad clásica, poseía una enorme trascendencia, en cuanto a prestigio y solidez argumentativa se refiere ${ }^{13}$.

Pero el asunto no terminaba aquí. La fiebre de los descubrimientos, por momentos histérica, fue hallando, a la par, una serie de láminas de plomo delgadas que terminarían siendo denominadas como los famosos Libros plúmbeos. Aquellas pequeñas planchas, de entre 60 y 70 milímetros y cosidas entre ellas por hilo de plomo, tenían caligrafía tanto árabe como latina. La autoría de los mismos se atribuía a Tesifón y a Cecilio. En total, entre 1595 y 1599, aparecieron veintiún libros que, unidos al pergamino encontrado en la Torre Turpiana, formaban un conjunto de veintidós documentos ${ }^{14}$.

12. Según parece, en los libros plúmbeos, influyen las tradiciones medievales que se recogían en las historias sobre los Siete Varones Apostólicos, y que los falsificadores usarían como patrón para sus relatos. F.J. Martínez Medina. "Los hallazgos del Sacromonte a la luz de la Historia de la Iglesia y de la teología católica", en Los plomos del Sacromonte..., pp. 93-96.

13. A.L. Cortés Peña. "Andalucía y la Inmaculada Concepción en el siglo XVII", en Religión y política durante el Antiguo Régimen. Granada, 2001, p. 109. Similar idea la encontramos en F.J. Martínez Medina. Cultura religiosa en la Granada renacentista y barroca. Estudio iconológico. Granada, 1989 , p. 265.

14. El nombre de los mismos es el que sigue: Libro del Fundamento de la Iglesia, Libro de la esencia de Dios, Oración y defensorio de Santiago, Ritual de la misa de Santiago, Libro de la predicación de Santiago apóstol o Catecismo mayor, Llanto de Pedro apóstol (la segunda parte del anterior), Libro de los hechos de nuestro Señor Jesús y de la Virgen María, Parte primera de lo comprensible del divino poder, clemencia y justicia sobre las criaturas, Historia del sello de Salomón, Relación de la casa de la paz y de la venganza y de los tormentos, De la naturaleza del ángel y de su poder, Sentencias 
La intencionalidad de toda esta gran historia ficticia, aludía a razones relacionadas con la convivencia de las dos culturas existentes en aquella Granada ${ }^{15}$. Tradicionalmente, estas invenciones fueron atribuidas a los moriscos Miguel de Luna y Alonso del Castillo, eruditos que gozaban del favor de Felipe $\mathrm{II}^{16}$. En un contexto en el que acababa de acontecer el levantamiento morisco y su posterior represión, y donde se barajaba la expulsión definitiva de estas gentes, unas supuestas revelaciones pseudo-divinas que defendían lo árabe e incluso lo proponían como modelo, suponían un intento de estrechar puentes entre ambas culturas, un sincretismo que permitiese coadyuvar a una convivencia pacífica entre ambos credos. Pero eso no sucedió. Los argumentos encontrados en el contenido de los libros, llevaron a una reafirmación mayor de los postulados cristianos, cargándolos de razones y fundamentando sus orígenes de fe.

Rápidamente comenzó el proceso de calificación de dichos descubrimientos. Se pretendía de este modo, dictaminar la veracidad y autenticidad de lo hallado. Por un lado, tanto el arzobispo Castro como la monarquía fueron fervientes defensores de la legitimidad de dichos hallazgos. En contraposición, varios teólogos, el Nuncio e incluso la Santa Sede, se mostraron cautos, contrarios e incluso intentaron disuadir constantemente la pasional gestión que el prelado granadino ejercía en este asunto. Ejemplo de esto, lo encontramos en el P. Ignacio de las Casas. Siendo como era ferviente defensor del misterio inmaculista, no se deja impresionar por las supuestas pruebas que los libros plúmbeos aportaban en esta cuestión. Más bien ve en ellas pruebas de herejía. En concreto, de nestorianismo. Según él, los argumentos que estos textos esgrimían negaban la divinidad de Jesús. Analizando el párrafo Adán fue sin padre ni madre; Eva de padre sin madre, Jesús de madre sin padre, y en esta generación no alcanzó a María el pecado primero, afirma lo siguiente: En lo que dice de la Puríssima Concepción de la Nuestra Señora, aunque el lugar es bueno para lo que deseamos ver de Fee,

sobre la fe, Libro de la Certidumbre del Evangelio, Historia de la Certidumbre del Evangelio, Libro de los enigmas y misterios que vio la Virgen en su coloquio con Dios, Del galardón de los creyentes en la "Certidumbre del Evangelio", De los grandes misterios que vio Santiago apóstol en el Monte Santo, Parte primera de los Hechos del apóstol Santiago y Parte Segunda de los hechos del apóstol Santiago. A estos hay que unir dos libros de los que nunca se descifró el texto, los considerados mudos, y el mencionado pergamino de la Torre Turpiana.

15. En ese sentido, son clarificadoras las palabras de Cabanelas al explicar la intencionalidad de estos escritos: Intentan al menos salvar una parte de su herencia espiritual mediante la incorporación de algunas de sus doctrinas [ ] un sincretismo de doctrinas musulmanas y cristianas, un posible credo común que resultase igualmente aceptable para los seguidores de ambas religiones, incluyendo en él las doctrinas islámicas que menos pudieran chocar a los cristianos y viceversa. En este conjunto de elementos sensiblemente heterogéneos, se admite la supremacía del Papa, la doctrina de la Inmaculada Concepción, la venida del apóstol Santiago a España, etc; todo ello sobre un fondo monoteista en sentido islámico, en el que Jesucristo, naturalmente, no aparece como hijo de Dios, sino como una manifestación del Espíritu de Dios. D. Cabanelas. "El Sacromonte punto de confluencia doctrinal entre Islam y la Cristiandad", en La Abadía del Sacromonte. Exposición artístico-documental. Estudios sobre su significación y origen. Granada, 1974, pp. 37-38.

16. Parece ser que en el grupo de falsificadores se encontrarían también personas conocedoras de la teología católica y de la historia de la Iglesia, o sea, que habría teólogos eclesiásticos. F.J. Martínez Medina. "Los hallazgos del Sacromonte...", p. 92. 
se puede explicar que quando María concibió al Hijo de Dios no alcanzó a la Sacratísima Humanidad el pecado original, y si el libro fue corrompido por hereges, y más Nestorianos, más parece que tira a esto el negarle la Divinidad que es lo que pretenden estos libros secretamente y dándole lo que nosotros damos a su sacratíssima madre. La exclusión del pecado original no habría afectado a la concepción de María por parte de Santa Ana, como defenderá el dogma de la Inmaculada, sino a la de Jesús ${ }^{17}$.

Convocado un concilio provincial a tal efecto el 1 de abril de 1600, a fecha de 30 del dicho mes, se publicaba un decreto en el que se consideraban como auténticos, tanto los restos humanos encontrados en el Sacro Monte, como lo hallado en la Torre Turpiana ${ }^{18}$. La Santa Sede siempre se mantuvo recelosa en la cuestión. Si bien permitió la calificación de las reliquias, mediante varios breves, insistió claramente en atenerse a lo dictaminado en Trento y, firmemente, en no tratar lo referente a los libros ${ }^{19}$. El tiempo terminó por desmoronar todo ese gran invento que, objetiva y fríamente, apenas se sostenía por sus propias contradicciones. El mismo Clemente VIII, ya en 1603, los consideraba una fábula. Una vez fallecido el arzobispo Castro, los libros fueron llevados en 1632 a Madrid, con la finalidad de ser trasladados finalmente a Roma con vistas a su traducción. Esto ocurriría finalmente en 1642, a pesar de la resistencia de los canónigos sacromontanos ${ }^{20}$. El desenlace de la historia estaba servido.

A fecha de 6 de marzo de 1682, mediante el Breve Ad circunspectam Romani Pontificis, se condenaban los libros plúmbeos del siguiente modo:

...se debian prohibir, y condenar los dichos Libros, y todo lo contenido en las laminas de plomo, membrana, o cartas referidas; porque falsamente se atribuyen a la Beatissima Virgen MARIA, al Santo Apostol Santiago el Mayor, o dictandolo el, a sus Discipulos Thesiphon, y Cecilio: antes son puras ficciones humanas fabricadas para ruina de la Feé Catholica; y respectivamente contienen heregias, y errores condenados por la Iglesia, y se oponen a la Letra de la Sagrada Escritura, Exposicion de los Santos Padres, y al uso de la Iglesia. Demas de que muchas cosas tienen resabios de Mahometismo, y parece, que no inducen poco a los Fieles a la Secta de Mahoma; conociendose, que no poca parte de ellos esta sacada, o copiada de su Alcoran, $y$ de otros Impurissimos Libros de los Mahometanos ${ }^{21}$.

17. R. Benítez Sánchez-Blanco. "De Pablo a Saulo: traducción, crítica y denuncia de los Libros plúmbeos por el P. Ignacio de las Casas, S.J.”, en Los plomos del Sacromonte..., pp. 236-237.

18. F. Bermúdez de Pedraza. Historia eclesiástica de Granada ..., ff. 19 v-20 r.

19. Los breves en cuestión son: Ex prioribus fraternitatis tuae, de 15 de enero de 1596, Ex compluribus fraternitatis tuae litteris, de 1 de septiembre de 1597 y Dudum cum ex tuae fraternitatis, de 1 de julio de 1598. F.J. Martínez Medina. "El Sacromonte de Granada y los sacromontes...”, pp. 16-17.

20. J. Antolínez de Burgos. Historia eclesiástica de Granada..., p. 655.

21. D. de la Serna Cantoral. Vindicias catholicas granatenses: relacion breue de las reliquias que se hallaron en la ciudad de Granada en una torre antiquissima, y en las cauernas del Monte Illipulitano de Valparayso cerca de la ciudad, sacado del processo y aueriguaciones, q cerca dello se hizieron. Leon de Francia, 1706, p. 263. 
Como apostilla final de toda esta invención, llama la atención cómo se llegó a calificar una parte como verdadera y la otra fuese condenada. Si una se basaba en la otra y viceversa, resulta curioso que no fuesen sancionadas de igual modo a la par.

\section{InMaculismo y Sacro Monte}

Tal y como venimos relatando, los descubrimientos que se produjeron a finales del Quinientos, supusieron para Granada una conmoción generalizada. La complejidad de los mismos ha sido estudiada desde muy diferentes enfoques y desbordaría por completo pretender abarcarla en su totalidad. Como es conocido, los tres grandes bloques temáticos que abordan los libros plúmbeos son los concernientes a la Virgen María, el apóstol Santiago y las tradiciones sobre San Cecilio. Ahora bien, teniendo en cuenta la personalidad tan visceral del arzobispo don Pedro de Castro, no es descabellado pensar que parte de la repercusión que en la sociedad granadina y española del XVII tuvieron los mencionados hallazgos, se debió al tema inmaculista que de ellos se desprendía. En este sentido, no olvidemos la devoción tan particular que el prelado profesaba hacia este misterio. Las referencias que sobre esto aparecían en los libros, enardecieron aún más su fervor concepcionista. No en vano, a lo largo de los siglos, esta postura no había dejado de ser una creencia piadosa y, en cierto modo, un simple entretenimiento teológico en las universidades medievales, para una élite de pensadores escolásticos. Aquellas disputas clásicas entre franciscanos y dominicos no habían salido de las aulas. A partir de este momento, el asunto va a salir a la calle y, teniendo al arzobispo Castro como adalid, desde su llegada a la diócesis de Sevilla, la cuestión se tornará pasional hasta extremos febriles.

De este modo, podemos afirmar, sin lugar a dudas, que con don Pedro de Castro y con los descubrimientos del Sacro Monte, se va a producir un antes y un después en el tema concepcionista en España. Ambos, prelado y hallazgos, van de la mano. De igual modo, el inmaculismo hispano va a convertirse en una cuestión de primer rango, a nivel nacional, gracias a este personaje $\mathrm{e}^{22}$.

La razón de todo este estado de fervor frenético, se debe a que el prelado había creído encontrar argumentos a sus ideas preconcebidas. Esto es, su devoción a dicho misterio era confirmada en los hallazgos sacromontanos, y no de cualquier modo, sino mediante poco menos que con revelaciones divinas ${ }^{23}$. Esa sensación de haber desenterrado un mensaje similar al de los evangelios o que, incluso lo

22. En este sentido, Barrios Aguilera considera que, de algún modo, al sector eclesiástico le resultaba difícil aceptar la relación de los términos D. Pedro de Castro-Inmaculismo-Plomos del Sacro Monte, ya que supondría aceptar que uno de los dogmas más importantes y entrañablemente queridos por la Iglesia Católica, tiene su fundamento en una superchería tan flagrante, perpetrada por moriscos y repleta de doctrinas islámicas. M. Barrios Aguilera. "Pedro de Castro y los Plomos del Sacromonte: invención y paradoja. Una aproximación crítica”, en: Los plomos del Sacromonte..., p. 47, nota 91.

23. S. Stratton. La Inmaculada Concepción en el arte español. (Tirada aparte de Cuadernos de Arte e Iconografia). Madrid, 1988, p. 52. 
completaba, se extendió en aquel ambiente. Clarificadoras, en este sentido, son las palabras de Diego de la Serna Cantoral:

Sobrevino a la solemne calificacion de las Reliquias el feliz hallazgo (en la Version, que se empezó a hacer de uno de los Libros) del Mysterio dela Purissima Concepcion; y aunque hasta entonces no avia salido de los Claustros esta disputa; transcendió en un instante a todo el Reyno de modo, que el mas eficaz argumento assi para el Mysterio, como para la verdad de los Libros, se sacó del sobrenatural poderoso influxo, conque en breve se produxo el maravilloso efecto de una universal conmocion, y acceptacion en todo el Reyno de España y aún en la Iglesia, del Mysterio (que disputado, y controvertido en otros, avia caminado a tan lentos passos en muchos Siglos) y originandose la exaltacion, que oy tiene, de la Sentencia que se descubrió en Granada ${ }^{24}$.

Por esta razón, en el contenido de los libros, el eje principal no sea otro que la figura de la Virgen. Tal y como ha estudiado el profesor Martínez Medina, en dichos plomos María aparece como la gran depositaria del mensaje de Dios, la que lo revela y enseña, la gran maestra de la Nueva Iglesia. Ella fue constituida por el mismo Dios, junto con los Apóstoles como «testigos de la Verdad» [ ] la encargada de revelar a los discípulos la Verdad del Evangelio ${ }^{25}$. De este modo, tal y como sugiere este autor, en estos textos encontramos un auténtico tratado sobre la Virgen, una completa mariología en la que se abordan temas dogmáticos como su virginidad perpetua o su maternidad divina mediante la Encarnación, todo ello muy influenciado por un discurso popular, basado en los evangelios apócrifos y en tradiciones de tipo devocional ${ }^{26}$.

Ahora bien, desde el punto de vista que nos atañe, el inmaculismo, resulta interesante hacer un esbozo del mismo según lo que hallamos en los libros plúmbeos.

La sentencia que ha quedado como referencia para la posteridad y que se convirtió en la leyenda y lema, tanto del escudo del Sacro Monte, como en el anagrama episcopal de don Pedro de Castro, fue la conocida frase A María no tocó el pecado primero. Tal frase se extraía de uno de los libros hallados ${ }^{27}$, aunque no constituye la única alusión a dicha cuestión que encontramos en tales documentos. En total, y contando esta reseña, encontramos diez citas que mencionan la pureza de la Virgen ${ }^{28}$ :

24. D. de la Serna Cantoral. Vindicias catholicas granatenses..., p. 2.

25. F.J. Martínez Medina. "El Sacromonte de Granada y los discursos...,", p. 27.

26. Ibidem, pp. 28-29.

27. La traducción que ofrecemos es la que realizó de los mismos textos Hagerty: Fue formado Jesús con madre sin padre, y asi a María no le comprendía el pecado original. "Libro de los fundamentos de la Ley de Tesiphon Aben Athar, discípulo de Jacobo, apóstol", en M.J. Hagerty. Los libros plúmbeos del Sacromonte. Madrid, 1980, p. 65.

28. El profesor Martínez Medina las extrae en el siguiente artículo: F.J. Martínez Medina. "El Sacromonte de Granada y los discursos...", pp. 29-31. 
- Fue Nuestro Señor Jesús hijo de María Virgen pura, hebreo ${ }^{29}$.

- Y cuando hubo muerto la Virgen pura establecieron sobre el monte en concilio el dividirse por el mundo ${ }^{30}$.

- En senado por Santa María Virgen pura, a Jacobo, hijo de Xameh, el Zebedeo, apóstol ${ }^{31}$. (Se repite en la misma página otra vez el calificativo virgen pura).

- Es María Virgen, pura del pecado en todas maneras, madre de Jesús, Espíritu de Dios $^{32}$. (Espíritu de Dios es traducido en el libro de Adán Centurión, Marqués de Estepa, por Verbo Encarnado de Dios) $)^{33}$

- Es Santa María, pura de pecado de todas maneras, madre del Espíritu de Dios, Jesús, intercesor tuyo en tu generación por la perdición ${ }^{34}$. (Madre del Espíritu de Dios es traducido en la obra de Adán Ceturión, Marqués de Estepa, por madre del Verbo Encarnado de Dios) ${ }^{35}$.

- Reparolo por Jesús después de la profecía de su venida en María, escogida con virginidad y pureza de pecado y exaltola sobre las mujeres del mundo exaltándola ${ }^{36}$. - Y si la comprendiera el pecado original se apartaran de ella sus hermosuras, y la tocara la aprobación en la concepción y en el parto tocándola ${ }^{37}$.

- Y aquella bendición es por ser ella limpia del pecado original ${ }^{38}$.

- Es la Virgen María, la limpia de pecado en todas maneras. Y la soberbia no la tocó nada de ella jamás ${ }^{39}$.

29. "Libro de los actos de Nuestro Señor Jesús y de sus milagros y de su Madre, María la Virgen”, en M.J. Hagerty. Los libros plúmbeos..., p. 95.

30. "Parte segunda del Libro de las acciones de Jacobo apóstol", en M.J. Hagerty. Los libros plúmbeos..., p. 243.

31. "Libro de las sentencias acerca de la Ley”, en M.J. Hagerty. Los libros plúmbeos ..., p. 185.

32. "Libro del coloquio de Santa María Virgen. Libro de las significaciones misteriosas que vio la Santa Virgen, María por gracia de Dios en la noche de su coloquio espiritual con él. De Jacobo, hijo de Xameh el Zebedeo, apóstol, escrito por mandado de ella por mano del notario y discípulo del apóstol Cecilio Aben Alradi", en M.J. Hagerty. Los libros plúmbeos..., p. 151.

33. A. Centurión. Traducción de los libros en Arabe escritos en laminas de plomo que con las reliquias de los santos Cecilio, Hiscio y Tesiphon, discípulos del apóstol Santiago se hallaron guardados desde aquel tiempo debajo de tierra cerca de Granada año de 1595. Hazíala con summa fidelidad y diligencia con sus interpretes Adan Centurión, marques de Estepa. S. I., siglo XVIII. (Copia digitalizada por la Biblioteca de Andalucía del texto que se halla en la Biblioteca Nacional), f. 62.

34. "Libro del coloquio de Santa María Virgen. Libro de las significaciones misteriosas que vio la Santa Virgen, María por gracia de Dios en la noche de su coloquio espiritual con él. De Jacobo, hijo de Xameh el Zebedeo, apóstol, escrito por mandado de ella por mano del notario y discípulo del apóstol Cecilio Aben Alradi", en M.J. Hagerty. Los libros plúmbeos..., p. 162.

35. A. Centurión. Traducción de los libros en Arabe escritos en laminas de plomo..., f. 67.

36. "Parte segunda de la noticia del divino poder", en M.J. Hagerty, Los libros plúmbeos..., p. 273 .

37. "Libro del conocimiento del divino poder y tolerancia y aceleración en las criaturas", en M.J. Hagerty, Los libros plúmbeos..., p. 267.

38. "Libro de los actos de Nuestro Señor Jesús...", en M.J. Hagerty. Los libros plúmbeos..., p. 97.

39. "Libro del coloquio de Santa María Virgen...”, en M.J. Hagerty. Los libros plúmbeos..., p. 155 . 


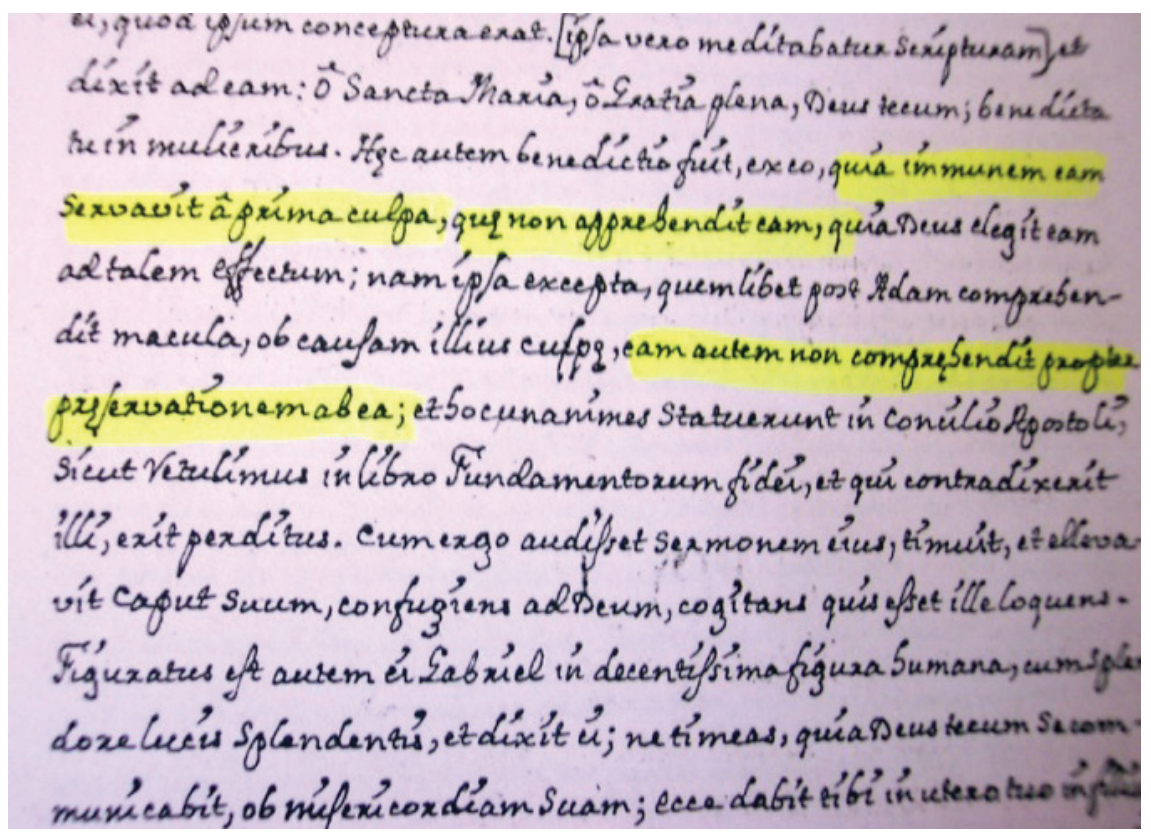

Fig. 1. Traducción original al latín de la sentencia "A María no tocó el pecado primero", extraída de los Libros Plúmbeos.

Asimismo, sobre la idea de que María estuvo limpia de pecado se dice que esto se decretó de conformidad en el concilio de los Apóstoles como referimos en el libro de los Fundamentos de la Ley. Y quien se desconformase de él será perdido ${ }^{40}$. Como es lógico pensar, esta última sentencia suponía una autoridad irrefutable en la defensa del dogma inmaculista. Si ya de antemano el prelado granadino era ferviente defensor de tal misterio, el encontrar unas supuestas revelaciones que atestiguaban la veracidad del mismo, nada más y nada menos que desveladas por la misma Virgen y por el apóstol Santiago, otorgaban una credibilidad indiscutible para instar a Roma a su definición dogmática ${ }^{41}$. Tal es así, que tal y como recoge Diego de la Serna Cantoral, don Pedro de Castro escribió al rey Felipe III sobre esto:

40. "Libro de los actos de Nuestro Señor Jesús...”, en M.J. Hagerty. Los libros plúmbeos..., p. 97.

41. Tal es así, que incluso dentro de la misma la disertación teológica, se va argumentar en favor de la definición dogmática, teniendo en cuenta como referente los hallazgos del Sacro Monte. F.J. Martínez Medina. "El Sacromonte de Granada y los discursos...”, pp. 36-52. Prácticamente desde el momento de los hallazgos, se va a relacionar el tema de las reliquias con el asunto de la Concepción. En una carta escrita por Jerónimo de la Higuera, que se conserva en el Sacro Monte, se aprecia dicha

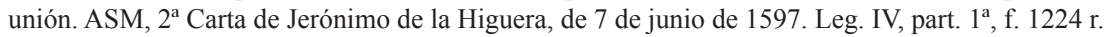


...impacientemente devoto al Mysterio de la Purissima Concepcion, cuya auctoridad incontrastable avia Dios puesto en sus manos; le pareció no detenerse un punto en aplicar, quantos medios fuessen possibles, para que con tal auctoridad, que era, la que se echava menos, passarsse la santa Iglesia a declararla por Mysterio. Escrivió al Señor Phelipe Tercero, haciendole cargo, de que en su tiempo se avia descubierto la mas segura noticia de la Concepcion, tan desseada antes dela Iglesia, y tan necessaria en tiempo, en que en las demas Provincias tanto se avia controvertido; y que, pues, Dios la puso en su mano en la Provincia de España, era su voluntad (al parecer) manifestar la eleccion del Rey Catholico, y a los Españoles para defensores de su inmunidad; y que assi devia interponerse su Catholico zelo con su santidad, para que con la noticia de tan indisputable fundamento, passasse a la declaracion, a que ya se avia empezado a inclinar la Iglesia en el decreto Tridentino ${ }^{42}$.

De este modo, el ambiente que se fue generando en torno a los libros plúmbeos y su contenido, sirvieron de caldo de cultivo para lo que posteriormente sucedería en Sevilla, una vez que don Pedro de Castro ya había tomado posesión de aquella sede en 1610. Los cimientos de la eclosión concepcionista que estallaría en el segundo decenio del siglo XVII, tendrían su origen, sin lugar a dudas, en los acontecimientos sacromontanos.

\section{Don Pedro de Castro y el Inmaculismo}

La centuria que marcó en España la cuestión inmaculista fue, sin lugar a dudas, la del Seiscientos. La controversia más acuciada, tanto a nivel popular como en las relaciones con la Santa Sede, se produjo en este siglo. Desde comienzos del mismo, hallamos referencias al tema concepcionista. El propio arzobispo Castro escribiría en el año 1602 una carta al rey Felipe III, interesándole sobre el tema y otra a Clemente VIII pidiéndole su definición dogmática. En el archivo del Sacro Monte hemos hallado esa epístola, que reproducimos íntegramente a continuación:

Muy sabido es la question de la conçepçion de nuestra señora, que hasta oy no sea determinado por la Iglesia y por Sixto 4 en la extrauagante commun y por el Conçilio de Trento, y por Pio quinto en una Bulla del año de. 1570. Se permitte tener la una oppinion, o la otra. Sancta Brigida en sus reuelaçiones approbadas por los Pontifiçes diçe en dos lugares auer sido conçebida sin pecado original, y que uerna tiempo que assi se declare. Quiça catholica Magestad por la misericordia de Dios a llegado este tiempo: porque los libros, que se hallaron en las cauernas de este monte Sacro, dizen y determinan, que en ninguna manera alcanço a Maria, ni la toco el peccado primero, y pone las gracias y mercedes que tuиo, que no las tuuiera, si ouniera sido conçebida en peccado original. Assi fue la oppinion de algunos, que tienen, que auia sido asi determinaçion, o tradiçion de los Appostoles, y auerlo predicado. Está esta oppinion tan asentada, y sosegada en

42. D. de la Serna Cantoral. Vindicias catholicas granatenses..., p. 90. Esta carta la reproducimos íntegramente más adelante. 
los entendimientos y corazones de los hombres, que nadie siente lo contrario, $n i$ osaria por escripto, ni de palabra. Parece que lo a madurado Dios y persuadido: para que con mas conformidad, y asenso del mundo lo pueda determinar la Iglesia. Resta que su Sanctidad sea servido de querer tractar de diffinir este articulo. Pareçe articulo breue, como yo lo tengo trauajado. No ay mas que tractar en el, sino satisfaçerse de la antiguedad, y uerdad de los libros, y yo e hecho muchas diligençias ordinarias, y extraordinarias: para la aueriguar. Por ella se auerigua, y con esta, que necessariamente son verdaderos, y ellos dan de si testimonio de su antiguedad, y exçelençia con el olor, y fragançia, que tienen. Es cosa marauillossa, que unos plomos, como son los libros, que todos estan escriptos en ojas de plomo, que tengan olor y fragançia, siendo la materia del plomo tan torpe y terrestre. $Y$ sea andado mucho deste camino en la qualificaçion, que se hizo de las reliquias del monte Sacro. Supplico humildemente a vuestra Magestad, como ya otras veces en las cosas deste monte Sacro me a hecho esta merced, sea vuestra Magestad seruido, que este articulo se tracte, y de informar, y supplicar al Rey nuestro señor que lo pida e inste a su Sanctidad. Si se acauase por su Magestad eternizaria su nombre, y seria perpetua su memoria: porque la Historia ecclesiastica es eterna, y mas en cosa tan grande, como es esto, y que a de auer diffiniçion de Pontifiçe Romano, y a cuya instancia sea hecho, y porque aueriguaciones. Las Historias temporales se pierden, y oluidan. Y está claro, que haciendo tanta honra a la madre de Dios, que a de pagar Dios nuestro señor, y nuestra señora, a quien este servicio le hiziere, $y$ dara al Rey nuestro señor estados, y Reynos, y larga Bendiçion, y a quien trauajare en ello, y yo hago mucho servicio a vuestra Magestad en lo acordar, e importunar. Pero porque esto a de tener dilaçion, y sea de probeer con deliberaçion y maduro consejo, como todo lo que determina la Iglesia supplico a vuestra Magestad humildemente, que entre tanto, que esto se vee, y determine, interçeda, e inste asu Sanctidad, me de liçencia: para publicar lo que diçen los dichos libros, que hallamos en las cauernas deste monte Sacro, que es lo que tengo dicho. Esto no prejudicando, ni innouando en nada, antes quedando en su vigor, y fuerça, lo que hasta aqui permite la Iglesia, que tenga cada uno la parte, y opinion $306 \mathrm{r} / /$ que quisiere. No abria de tener difficultad conçeder su Sanctidad, que esto se publicase, como tampoco la tenia el dar su Sanctidad, o vuestra Magestad liçençia, que luego la daria para imprimir un libro, en que se disputase esta question, y defendiese, no auer tenido peccado original. Dios guarde y ensalze la catholica persona de vuestra Magestad, como yo su Capellan deseo y se lo supplico. Del monte Sacro çerca de Granada ${ }^{43}$.

Las negociaciones del prelado fueron intensas, puesto que en la misma fecha, también va a escribir al Duque de Lerma solicitándole que interceda ante el rey, en favor de la definición de la Purísima ${ }^{44}$. No debieron tomar muy en serio en la Corte tantas insistencias de don Pedro de Castro, puesto que con fecha de 3 de diciembre de 1602, el Consejo Real intentó disuadir al arzobispo diciéndole que, con respecto al asunto de la Concepción, estando como está tan a cargo de su santidad, no ay para que se le pida la dicha difinicion ${ }^{45}$.

43. ASM, Leg. V, ff. 306 r-v. Una copia de esta carta es conservada en dicho archivo, estando fechada a 3 de septiembre de 1602. ASM, Leg. V, ff. 315 r-v.

44. ASM, Leg. V, ff. 317 r-v.

45. ASM, Leg. V, f. 323 r. 
De ese mismo año, Diego Nicolás Heredia Barnuevo, nos relata en su Místico Ramillete una historia ocurrida en el sitio de Íllar, perteneciente a la Taha de Marchena. No deja de ser una de esas tradiciones milagrosas atribuidas a la Virgen, pero que en aquel ambiente enfervorizado tras los descubrimientos sacromontanos, tomó un tinte inmaculista que, quizás en otro contexto, no lo hubiese adquirido:

Queria la Providencia dar a conocer al mundo con nuevas luces de culto y devocion la Concepcion Inmaculada de su bendita Madre, y como Granada y su Venerable Arzobispo habian de ser (como despues se verá) el oriente de este sol de la verdad, dispuso precediesen ciertos crepúsculos de esta divina aurora en un suceso milagroso, que sucedió el dia 4 de Marzo de este año [1602] en Illar, lugar de la Taha de Marchena, en este Arzobispado. El caso, como autenticado, se conserva en el archivo del Sacro-Monte. Sucedió asi. Al tiempo que cuatro virtuosas mujeres continuaban dicho dia por la tarde una devota novena a Nuestra Señora, advirtió una de ellas en una Imagen de talla de la Concepcion Purísima el prodigio de un milagroso sudor. Certificáronse de él todas con asombro, y corren gritando a la puerta de la Iglesia: Milagro, milagro de la Concepcion de Nuestra Señora. Corre la voz de unos en otros por el Pueblo, y a la novedad concurren piadosamente curiosos todos los vecinos. El primero fue el Licenciado Juan de Oliver, Beneficiado y Teniente de la Taha, acompañado de otros cuantos Sacerdotes, a los que ordenó limpiasen con unos Corporales las gotas de sudor que corrian por el rostro de la santa Imagen. Al ir a ejecutarlo grita el pueblo que sudaban tambien otras imágenes: una de Nuestra Señora con el Niño Jesús en los brazos, y otra de mi Señora Santa Ana, que estaban en otra Capilla. Acuden a ella los Sacerdotes, y admíranse al ver la rara maravilla de que corrian las gotas de sudor mas copiosas cuanto mas las enjugaban. Veinte y ocho horas estuvo sudando la Imágen de la Concepcion Purísima, y por mas de cuarenta las otras dos. Avisado el Vicario, que se hallaba en el cercano lugar de Albolodui, advirtió con muchos otros que ni habia sudado ni sudaba la Imágen del Niño Jesús, sudando con tanta abundancia las otras tres. Hace informacion jurídica de todo el caso. Forma otra por su parte el Consejo Secular, y ambas se remiten al Venerable Arzobispo, quien al punto dió comisión a uno de sus Provisores, para que pasase a fulminar proceso en la debida forma que requeria la averiguacion de tan singular portento. Hizose asi, y resultó de él la auténtica ejecutoria que citamos ${ }^{46}$.

Al hecho en cuestión se le dio una destacada importancia, puesto que la institución eclesiástica se interesó por el mismo. Al día siguiente del acontecimiento, el 5 de marzo, el beneficiado Juan de Oliver se ponía en contacto con el licenciado Juan de Ocampo, quien, escribiendo al arzobispo Castro, le solicitaba que en breve le indicara lo que se había de hacer:

El beneficiado Juan de Oliber que asiste en la villa de Yllar desta taha de marchena me enbio a llamar aier martes y anoche como teniente de vicario por ausencia de el licenciado Juan de la trinidad que lo es y dandome abiso de que

46. D.N. Heredia Barnuevo. Mistico ramillete..., pp. 106-107. 
en su yglesia abia sucedido cierto milagro yo acudi luego esta mañana a la dicha billa donde halle en la yglesia muncho numero de jente que abia concurrido de toda la taha a la fama de ello halle a la justicia ordinaria haciendo informacion en razon de que una ymagen de nuestra señora de bulto y otra de señora sancta ana y una de nuestra señora anbas en una hechas de talla dorada abian sudado beinte y seis oras sin cesar aunque munchas beces seles abia linpiado los rostros se bolbian a rrenobar de el dicho sudor sobre lo qual yo hice la informacion que constaba que por ser cosa tan notoria no quise se hiciesen mas dilijencias hasta dar cuenta dello a buesa señoria yllustrisima como lo hago y enbio las dilijencias fechas y ciertos testimonios de escribano $484 \mathrm{r} / / /$ que el licenciado oliber tenia para que por buesa señoria bisto mande lo que mas conbenga y asi en esta no digo mas de suplicar a buesa señoria yllustrisima se me enbie a mandar con brebedad lo que acerca de esto se debe hacer esto de parte mia y de la del concejo y becinos desta uilla acuia instancia se despacho el portador que no ba a otra cosa guarde nuestro señor a buesa señoria yllustrisima y acreciente en maior dignidad como por sus criados se desea en yllar a. 5. de marzo. de 1602 años. Licenciado Nuñez de Ocampo $^{47}$.

Pero el asunto revestiría tal importancia en aquella atmósfera crédula y propicia a sucesos taumatúrgicos que, entre la documentación, también hemos hallado el informe que realizó nada menos que Justino Antolínez de Burgos. En la carta que remite al arzobispo el día 6 de marzo, aparte de dar por seguro y probado el milagro, insta al prelado a determinar qué se ha de hacer:

El lunes que se contaron quatro de el presente como a las quatro de la tarde en la yglesia de esta villa estando y abiendo una novena quatro mugeres de instincion de buena vida y costumbres una ymagen de la advocacion de la concepcion que por tener un rosario en las manos la llaman del el Rosario sudó en abundancia como consta de los testimonios de escrivano público que sobre ello pedi y en esta misma ora y puncto sudaron asimismo una ymagen de señora santa ana y hija y nieto que estan todas tres en una eccepto el niño que prometo a vuestra señoria que a la ora que llegué a mi yglesia que fue otro dia siguiente antes de puesto el sol vide y limpié el sudor de las dichas tres ymagenes por mas de tres veces y haciendo tiempo y tomando testimonio por escrivano como constara delos papeles que con esta ban y de estas veces que yo las limpié y de otras 487 r// que otros sacerdotes limpiaron ay mas de mil testigos con ser este lugar de treinta y dos casas por que fue tan grande la summa de gente que ocurrió en más de veinte y ocho oras que sudaron sin cesar las dichas ymagines y aunque aun es el número mayor de lo que dicho tengo visto lo que tengo referido y siendo caso no sucedido en este lugar y digno de admirar yo hice la diligencia posible para aberiguar la verdad del succeso y assi llegué a las dichas ymaginas con la mayor reverencia que pude en compañia de quatro sacerdotes y el escrivano deste juzgado y descubri las cabeças y cuerpo parte por parte con mucho cuydado y se vido patentemente por el dicho sudor miraculoso por que tan solamente sudaban los rostros y las demas partes de el cuerpo estaban enjutas y con polvo como todo consta vuestra señoria lo vera y despues de remitida la informacion a vuestra señoria oy miercoles a las

47. ASM, Leg. I, part. $1^{\mathrm{a}}$, f. $484 \mathrm{r}-\mathrm{v}$. 
tres oras de la tarde poco mas o menos vino a esta villa el beneficiado de alboloduy y llegando a ver las dichas ymagines vido ocularmente la dicha ymagen de señora santa ana sudar y para satisfazerse con un lienço llego con la decencia debido y limpió dos o tres gotas de sudor del rostro de la dicha señora santa ana que parece segun lo que dicho tengo y a más de quarenta oras que suda la ymagen de señora santa ana y las otras dos de nuestra señora sudarian como veinte y seis o veinte y ocho oras y he dado noticia a vuestra señoria de el caso ${ }^{487}$ vto.// para que en el se provea lo que vuestra señoria yllustrisima viere que combiene concluyo con que vuestra señoria se persuada que el milagro patente por la prueba que en él a auido y nuestro señor guarde a vuestra señoria mill años con el augmento que todos deseamos. yllar. y março. 6. de $1602^{48}$.

Tras estas diligencias, no sabemos qué sucedió después ni cuál fue el parecer final de don Pedro de Castro. Pero conociendo la personalidad del prelado, intuimos que se le dio una total verosimilitud y fue un acicate más en favor de sus tesis inmaculistas.

Un año después, en 1603, el arzobispo volverá a enviar a la corte una remesa de cartas, solicitando la definición dogmática del misterio inmaculista. En concreto, con fecha de 11 de abril de dicho año, escribirá tanto al rey como al Duque de Lerma. Al monarca, insistiéndole en la necesidad de la consecución del dogma. Al noble, pidiéndole que influyera sobre Felipe III, para que éste gestionara la mencionada cuestión ${ }^{49}$.

Con fecha de 3 de septiembre, don Pedro de Castro escribirá al Consejo Real que, por medio de su presidente, el Conde de Miranda, don Juan de Zúñiga, pide al rey, el día 5 de octubre, que tome cartas en el asunto. Así lo recoge Heredia Barnuevo:

Fervorizó este año [1603] el V. Arzobispo a sus dos Cabildos, el Ilustrísimo Eclesiástico y el Excelentísimo de la Ciudad, a promover la causa piadosa del misterio de la Concepcion Inmaculada. La carta del Arzobispo en este asunto, encendia mucho fuego de devocion al misterio; tanto, que prendió en los deseos de los sabios Licurgos, que componian entonces el Consejo Real de Castilla, quien consultó al Monarca, instándole a que tomase muy a su cargo este negocio. Asi consta de carta con fecha de 5 de Octubre de 1603 del conde de Miranda Don Juan de Zúñiga, Presidente de Castilla. No fué pequeña gloria de nuestro Prelado, ni será corto elogio a la posteridad de la nobilísima Granada haber sido el primer móvil que dió impulso a los progresos que ha hecho la piedad y culto de este misterio en España ${ }^{50}$.

Y es que el prelado Castro, consideraba que no se estaba haciendo lo suficiente en favor de la definición dogmática de la Concepción. En una nueva carta escrita al Duque de Lerma, donde rememora todas las misivas que había enviado a la Corte desde 1602, lamenta el poco interés con el que se había tomado tal

48. ASM, Leg. I, part. $1^{\text {a }}$, ff. 487 r - 488 r.

49. ASM, Leg. V, ff. 332 r. y 335 r.

50. Ibidem, p. 113. 
cuestión: ... A se tomado este negocio con tanta tibieça que poco o nada podra aprovechar la intercession y presencia del Arçobispo [ ] Y assi se a quedado olvidado una cosa tan grande y tan desseada en el mundo ${ }^{51}$.

\section{El INMACULISMO EXTENDIDO POR GRANADA DURANTE EL EPISCOPADO}

En otro orden de cosas, y valorando lo que supuso la expansión de la devoción concepcionista a comienzos del siglo XVII en Granada, tenemos que tener en cuenta otros aspectos. Interesante será la proliferación de memorias o fiestas dedicadas a la Concepción de la Virgen en la Catedral durante toda la centuria. Un ejemplo de estas primeras muestras al hilo de estos incipientes acontecimientos inmaculistas, lo hallamos en ese año de 1603. Según consta, el racionero de la Catedral Benito Ramírez, ante el escribano público Luis de Soria, creará una memoria para el día de la Concepción con vísperas, dotándola con la no despreciable cantidad de 140 ducados, que se debían repartir entre la fiesta de San Miguel, una de réquiem, y la dicha de la Concepción ${ }^{52}$.

La labor del prelado Castro había generado sus frutos. Interesante nos resulta un dato al final de su episcopado. Y es que, probablemente sus esfuerzos por insuflar el fervor concepcionista, contagiaron a otras instituciones. Este es el caso del Colegio de Niñas Nobles. En 1609, el rico genovés Bartolomé de Veneroso o Beneroso, fundaría este colegio bajo la advocación de la Concepción. Para su sostenimiento, en su testamento lega 40000 maravedís de renta perpetua ${ }^{53}$. Este Veneroso, sería el mismo que también fundase el Colegio de San Bartolomé, posteriormente fusionado con el de Santiago.

No debemos confundir este Colegio de Niñas Nobles con el que hubo situado en la calle Cárcel Baja. Dicha institución no tiene un origen claro, entremezclándose los datos y haciendo más confusa su historia. Gallego y Burín la remonta a 1530, bajo la fundación de doña Ana de Mendoza. Por el contrario, el jesuita Alonso de Ayala, otorga tal erección al que fuera Deán de la Catedral y provisor del arzobispado, Justino Antolínez de Burgos, quien dotaría la institución con 800 ducados.

51. ASM, Leg. V, f. 339 r.

52. Para la celebración de dicha memoria, debía asistir el colegio, distribuyéndose el dinero entre los capellanes que oficiaran. Asimismo, se había de cantar el prefacio y el paternoster, con cuatro cirios y alfombra. Las misas debían de celebrarse en el altar de la Virgen de la Antigua. ACGr, Libro de las memorias de los capellanes (1621), 21 C, f. 92 r.

53. Ytem mando se den cada año al colegio de las doncellas que se a començado en esta ciudad quarenta mill maravedis de renta perpetua mientras durare el dicho colegio. AHDGr, Sección Patronatos, Testamento de Bartolomé de Veneroso otorgado en 1609, Leg. 52, pza. 1, f. 16 r. Aunque en su testamento no se especifica el nombre de dicho colegio, en otro texto donde encontramos también la misma documentación, hallamos la siguiente referencia: ... al dicho collegio de las donzellas desta dicha ziudad adbocazion de la conzepzion. Dicho colegio estaba situado en el Hospital de la Caridad. AHDGr, Testamento de Bartolomé de Veneroso, Cajas de Archivo 25-B, s. f. 
Para nuestro interés, lo que conviene resaltar es que dicho colegio también fue puesto bajo la advocación de la Concepción ${ }^{54}$. Don Pedro de Castro, le daría a fecha de 9 de octubre de 1607 unas constituciones para su funcionamiento. En ellas, el prelado disponía que, entre el personal del colegio, debía haber una rectora, una maestra, una provisora y unas sirvientas al servicio de las niñas. Como institución femenina que era, su misión era enseñar a las doncellas a leer, escribir, coser, labores, la doctrina cristiana y todo lo que una mujer debía realizar en aquella época. Para la consecución de estos fines, se establecía una disciplina y un horario, semejante al de un convento religioso, donde las féminas eran instruidas, o bien para la vida consagrada, o bien para el matrimonio ${ }^{55}$.

Estas leves referencias que hemos aportado no son baladíes. Hemos de tener en cuenta que, desde el punto de vista inmaculista, anteriormente a estos datos, pocas alusiones encontramos más. No hemos de olvidar que en Granada, debido a su tardía conquista, en el antiguo reino nazarí comenzaban a colocarse los puntales de elementos cristianos que en otras diócesis hacía tiempo que se habían consolidado. En el caso de la dotación de misas para la Purísima Concepción en la Catedral por parte de un canónigo, por ejemplo, la primera referencia que encontramos data de $1530^{56}$.

Esto, finalmente, nos lleva a colegir una conclusión, la suma importancia que el prelado Castro tuvo en la extensión de la devoción concepcionista en Granada. El inmaculismo en estas tierras va a tener un antes y un después tras su paso por la archidiócesis. Desde nuestro punto de vista, la figura de este arzobispo es enormemente interesante. Si bien puede llegar a parecer que ha pasado a la historia como un iluso, un ingenuo o un necio que se dejó engañar por la mentira de unos libros plúmbeos, que terminaron siendo condenados una vez ya había fallecido para no desautorizarlo, nosotros pensamos de otro modo. Desde nuestro punto de vista, una persona que llegó a ser doctor y presidente de las dos Chancillerías, no creemos que pecase de estulticia. Más bien todo lo contrario. Supo aprovechar y manejar ideológicamente el relato sacromontano para sus propios fines. Creemos que interpretó a la perfección la intencionalidad originaria de los autores de los libros plúmbeos y recondujo aquellos acontecimientos para, por un lado, reafirmar sus creencias inmaculistas, que por aquel entonces eran aún una mera opinión teológica; asimismo, en un universo donde las reliquias eran casi un dogma de fe, aprovechó todo el material que le proporcionó el Monte Valparaíso para construir una Abadía, poner el nombre de Granada nuevamente en el candelero (con todo lo

54. ... lo qual a sido por el amparo y protección que nos a dado en su benditisima Madre teniendola por Madre y señora cuyas virtudes deuen imitar. En reconocimiento desto encargamos que al tiempo de acostarse a la noche y lebantarse a la mañana sea la primera y ultima accion hincarse de rodillas adorando a nuestra Señora y benerando su limpisima concepcion entregandose cada dicha por sierua fiel desta soberana Señora y pidiendole su bendiçion// y amparo en todo. ACGr, Constitución y Consueta del Colexio de las Niñas Nobles Huerfanas de Granada, Leg. 9, pza. 19, s. f. Toda la documentación original de dicha constitución se halla en el mencionado legajo.

55. M.C. Calero Palacios. Enseñanza y educación en Granada bajo los reyes Austrias. Granada, 1978, pp. 377-385

56. ACGr, Patronato fundado por el bachiller Pedro de Villate, canónigo de la Santa Iglesia de Granada, s. f. 
que ello suponía) tras los luctuosos sucesos de la Guerra de las Alpujarras, y de camino, establecer un lugar de peregrinación de origen casi apostólico, con pingües beneficios económicos añadidos. Por esta razón, podemos concluir afirmando la trascendencia que tuvo este prelado en el tiempo que estuvo al frente del arzobispado, no sólo desde el punto de vista meramente concepcionista, sino también a nivel histórico. Personaje del que aún quedan por analizarse muchos aspectos.

\section{BIBLIOGRAFÍA.}

Alonso, Carlos. Los apócrifos del Sacromonte (Granada). Estudio histórico. Valladolid, 1979.

Antolínez de Burgos, Justino. Historia eclesiástica de Granada. (Edit.) M. Sotomayor. Granada, 1996.

Barrios Aguilera, Manuel. "Moriscos y cristianos en el orto de la Granada Moderna", en Jesucristo y el Emperador cristiano, Córdoba, 2000.

- " "Pedro de Castro y los Plomos del Sacromonte: invención y paradoja. Una aproximación crítica", en Los plomos del Sacromonte. Invención y tesoro. Valencia, 2006.

Benítez Sánchez-Blanco, Rafael. "De Pablo a Saulo: traducción, crítica y denuncia de los Libros plúmbeos por el P. Ignacio de las Casas, S. J.”, en Los plomos del Sacromonte. Invención y tesoro. Valencia, 2006.

Bermúdez de Pedraza, Francisco. Historia eclesiástica de Granada. Granada, 1989.

Bonet Correa, Antonio. "Entre la superchería y la fe: el Sacromonte de Granada", Historia 16, 61 (1981).

Cabanelas, Darío. El morisco granadino Alonso del Castillo. Granada, 1965.

_. "El Sacromonte punto de confluencia doctrinal entre Islam y la Cristiandad", en La Abadia del Sacromonte. Exposición artístico-documental. Estudios sobre su significación y origen. Granada, 1974.

Calero Palacios, M Carmen. Enseñanza y educación en Granada bajo los reyes Austrias. Granada, 1978.

Caro Baroja, Julio. Las falsificaciones de la Historia en relación con la de España. Barcelona, 1992.

Centurión, Adán. Información para la historia del Sacro monte, llamado de Valparaiso y antiguamente Illipulitano junto a Granada. S. 1., s. a. (Copia digitalizada de la Biblioteca Virtual de Andalucía).

- Traducción de los libros en Arabe escritos en laminas de plomo que con las reliquias de los santos Cecilio, Hiscio y Tesiphon, discípulos del apóstol Santiago se hallaron guardados desde aquel tiempo debajo de tierra cerca de Granada año de 1595. Hazíala con summa fidelidad y diligencia con sus interpretes Adan Centurión, marques de Estepa. S. I., siglo XVIII. (Copia digitalizada por la Biblioteca de Andalucía del texto que se halla en la Biblioteca Nacional).

Cortés Peña, Antonio Luis. "Andalucía y la Inmaculada Concepción en el siglo XVII”, en Religión y política durante el Antiguo Régimen. Granada, 2001. 
Hagerty, Miguel José. Los libros plúmbeos del Sacromonte. Madrid, 1980.

Henríquez de Jorquera, Francisco. Anales de Granada. (Edit.) A. Marín Ocete. Granada, 1987.

Heredia Barnuevo, Dionisio Nicolás. Místico ramillete. Vida de D. Pedro de Castro, fundador del Sacromonte. (Edit.) M. Barrios Aguilera. Granada, 1998.

Martínez Medina, Francisco Javier. Cultura religiosa en la Granada renacentista y barroca. Estudio iconológico. Granada, 1989.

—. "El Sacromonte de Granada y los discursos inmaculistas postridentinos", Archivo Teológico Granadino 59 (1996).

—. "El Sacromonte de Granada y los sacromontes: mito y realidad", Proyección 44 (1997).

-. "El Sacromonte de Granada, un intento de reinculturación entre la guerra de los moriscos y su definitiva expulsión”, Chronica Nova 25 (1998).

-. "El Sacromonte de Granada: impulsor de la Inmaculada Concepción en la Contrarreforma", en A María no tocó el pecado primero. "La Inmaculada en Granada”. Córdoba, 2005.

- "Los hallazgos del Sacromonte a la luz de la Historia de la Iglesia y de la teología católica", Al-Qantara 23 (2002).

—. "Los Libros Plúmbeos del Sacromonte de Granada", en: Jesucristo y el Emperador cristiano. Córdoba, 2000.

Peinado Guzmán, José Anatonio. Controversia teológica. Devoción popular. Expresión plástica. La Inmaculada Concepción en Granada. Granada, 2012.

Pita Andrade, José Manuel. Museo del Sacromonte. Granada, 1964.

Ramos, J. El Sacro Monte de Granada. Madrid, 1883.

Royo Campos, Zótico. Reliquias martiriales del Sacromonte. Granada, 1960.

-. Albores del Sacromonte. Granada, 1958.

- Don Pedro de Castro, caudillo insigne del concepcionismo en España. Granada, 1954.

- El insigne Colegio del Sacromonte y la Universidad de Granada. Granada, 1954.

Sánchez-Mesa Martín, Domingo. "Aportaciones al estudio de la escultura religiosa en el Sacromonte", en La Abadía del Sacromonte. Exposición artísticodocumental. Estudios sobre su significación y orígenes. Granada, 1974.

Serna Cantoral, Diego de la. Vindicias catholicas granatenses: relacion breue de las reliquias que se hallaron en la ciudad de Granada en una torre antiquissima, y en las cauernas del Monte Illipulitano de Valparayso cerca de la ciudad, sacado del processo y aueriguaciones, q cerca dello se hizieron. Leon de Francia, 1706.

Stratton, Suzanne. La Inmaculada Concepción en el arte español. (Tirada aparte de Cuadernos de Arte e Iconografia). Madrid, 1988.

Fecha de recepción del artículo: agosto de 2014

Fecha de aceptación y versión final: enero de 2015 
